\title{
Power system reliability assessment in a complex restructured power system
}

\author{
N. Mahiban Lindsay ${ }^{1}$, A. K. Parvathy ${ }^{2}$ \\ ${ }^{1}$ Department of Electrical and Electronics Engineering, Hindustan University, India \\ ${ }^{2}$ Department of Electrical Engineering, Hindustan University, India
}

\section{Article Info \\ Article history: \\ Received Feb 13, 2018 \\ Revised Jun 19, 2018 \\ Accepted Mar 9, 2019}

\section{Keywords:}

DAFOR

EENS

IEEERTS

Performance indices

System reliability

\begin{abstract}
The basic purpose of an electric power system is to supply its consumers with electric energy as parsimoniously as possible and with a sensible degree of continuity and quality. It is expected that the solicitation of power system reliability assessment in bulk power systems will continue to increase in the future especially in the newly deregulated power diligence. This paper presents the research conducted on the three areas of incorporating multistate generating unit models, evaluating system performance indices and identifying transmission paucities in complex system adequacy assessment. The incentives for electricity market participants to endow in new generation and transmission facilities are highly influenced by the market risk in a complex restructured environment. This paper also presents a procedure to identify transmission deficiencies and remedial modification in the composite generation and transmission system and focused on the application of probabilistic techniques in composite system adequacy assessment.
\end{abstract}

Copyright () 2019 Institute of Advanced Engineering and Science. All rights reserved.

\section{Corresponding Author:}

N. Mahiban Lindsay,

Departement of Electrical and Electronics Engineering,

Hindustan University,

No.1, Padur, Chennai, 603103-India.

Email: nmlindsay@hindustanuniv.ac.in

\section{INTRODUCTION}

Electricity is a very efficacious and reliable form of energy and it can be generated through various means, delivered efficiently, securely and economically. In order to identify the quandary between the economic and reliability constraints, many design and planning operation techniques have been developed and applied in the electric power industry over many years $[1,2]$. Most of these criteria are deterministically based and some of are probabilistic in nature which is used in many reliability analysis. Many authors were reported various simulation and probabilistic techniques for the power system reliability assessment [3-5]. In the field of major generating units and transmission planning, more and more utilities are attempting to integrate probabilistic techniques into their system evaluation because of the strategic importance of these facilities. Reliability is an intrinsic characteristic and a specific measure of any component, device or system, which describes its capability to perform its intended function. In a power system, the measures of reliability indicate how well the system performs its basic function of supplying electrical energy to its customers [6, 7].

Many state space models are used to determine the reliability of restructured system but the failure rate was not abridged. To curtail the outage rate there is a need of an efficient progressive algorithm to determine the load point reliability indices and enchance system reliability in the restructured power system [8]. Incorporating derated states in large generating unit models can create a considerable increase in the number of generation contingency states and therefore result in a momentous increase in the overall solution time when using the enumeration approach $[9,10]$. The responsibility of Transcos and ISOs is to see that the required electricity is delivered reliably and economically to the system consumers [11]. 
The objective of the research conducted in this area is to examine the exploitation of composite system adequacy assessment to determine the transmission deficiencies in systems where generation resources are decoupled from transmission investment. Two-state generating unit models concerning derating adjusted forced outage rates (DAFOR) are usually used to conduct both generating capacity and composite generation and transmission system reliability studies rather than multi-state unit models. This paper presents a procedure to identify transmission deficiencies in composite generation and transmission system adequacy assessment. The proposed procedure includes three parts: base case analysis, factor analysis of the base case, and remedial modifications and their effects. The modified versions of these test systems reflect possible transmission constraints in the new market environment.

\section{RESEARCH METHOD}

The basic function of a complex generation and transmission system is to generate the required electricity and deliver it to the major load points. Complex system adequacy assessment is very important since it involves not only system analyses but also many practical deliberations [12]. The system analyses involved in the assessment include load flow studies, critical assessment, generation rescheduling, transmission overload alleviation, load curtailment, etc. Developing a suitable transmission network is very essential to transfer the power without any paucity to the distribution companies. Analytical methods represent the system by logical models and use arithmetical methods to evaluate the required reliability indices based on the state models [13, 14]. Reliability indices are an important outcome of quantitative adequacy assessment of a composite system. Both load point and system indices can be used to measure composite system adequacy. Load point indices indicate the reliability at the individual load buses while system indices provide an overall evaluation of total system reliability and reliability worth [15, 16]. The two sets of indices in the generation units and the load point have different functions but complement each other. Load point indices are usually used when the focus of the adequacy assessment is to find and strengthen defective buses in the system. System indices are used when the purpose of the adequacy assessment is to provide a global assessment of the system and to compare different alternatives. There is a wide range of load point and system indices that can be evaluated. Bulk system reliability indices can be divided into the two general categories of predictive and past performance indices [17]. In the first case, the indices are calculated based on component reliability data for the generation and transmission facilities and in the second case, the indices are compiled using statistical methods based on the actual operation of the bulk power system. Most predictive indices are related to adequacy assessment and estimate future system reliability. Past performance indices are normally associated with overall reliability assessment and include both adequacy and security considerations. These indices are usually used to provide general information on the reliability performance of bulk power systems and are discussed in detail.

\section{Calculation of load point indices}

There are two ways to determine the system and load point indices. The first method is to calculate the indices under peak load conditions and expressed them on a one-year basis and theassociated indices are then known as annualized indices. The second is to calculate from the load duration curve with all demand fators known as annual indices. Annual indices are the most useful indices as they incorporate the variations in load level and reflect the actual load profiles throughout the year. The advantage of annualized indices is that they require less computing period and can be used to roughly reflect the system reliability performance.

\section{INCORPORATING MULTI-STATE GENERATING ENTITY MODELS IN COMPOSITE SYSTEM ADEQUACY EVALUATION}

In this section, it is explained the results of research and at the same time is given the comprehensive discussion. Results can be presented in figures, graphs, tables and others that make the reader understand easily $[2,5]$. The discussion can be made in several sub-chapters.

Components are generally represented by two-state models in conventional generating capacity (HLI) and composite generation and transmission system (HLII) reliability studies [18, 19]. Multi-state generating unit models create a momentous increase in the number of generation contingency states and can result in a considerable increase in the overall solution time. In order to avoid this problem, the derated states are usually combined with the totally forced out state to create a derating adjusted forced outage rate (DAFOR). The DAFOR of a generating unit can be obtained using (1).

$$
\text { DAFOR }=\frac{\operatorname{Tdn} \sum_{N \epsilon 1}^{\mathrm{n}}\left(U_{x} t Y_{i}\right) \mathrm{N}}{\mathrm{T}}
$$


Multi-state generating unit models

The two 400-MW generating units and the 350-MW generating unit in the IEEERTS are taken for analysis, since the generating units are responsible for the diffraction of reliability in the base case [20]. The two state, three state, four state and five atate representation for the two 400-MW generating units is shown in Figure 1, Figure 2, Figure 3 and Figure 4 respectively. The derated adjusted forced outage rate is included from three state configurations which infer the improvement in the UP state. Due to the presence of DAFOR, the system reliability will be improved and having more contingency to decipher the system reliability in the restructured power system.

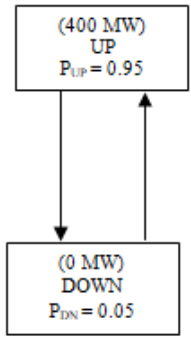

Figure 1. The two state models for 400-MW generating unit

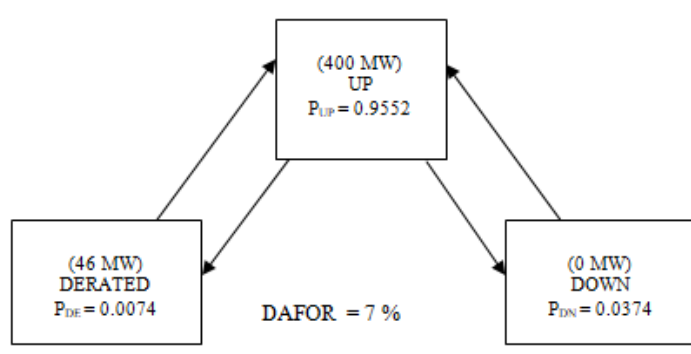

Figure 2. The three state models for 400-MW generating unit

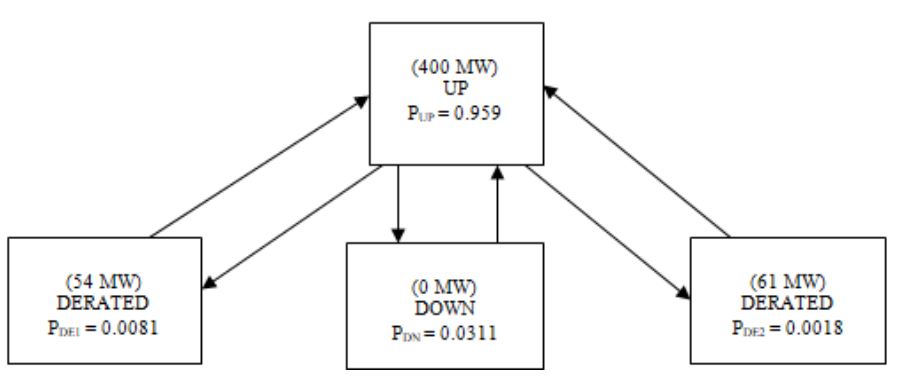

Figure 3. The four state models for 400-MW generating unit

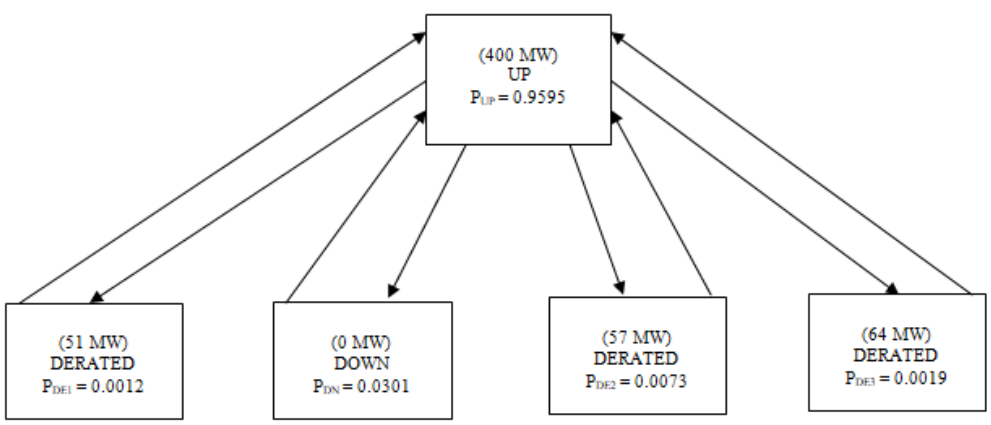

Figure 4. The five state models for 400-MW generating unit

The DAFOR in all the above models shown in Figure 4 is 0.07 . Simalarly the forced outage rate and the failure rate of $350 \mathrm{MW}$ generating units will be analysed. The different states of analysis with the derated adjusted forced outage rate give the solution to increase system reliability with reduced down time. The following state models shown in Figure 5, Figure 6, Figure 7 and Figure 8 represent the changes in the down time due to the presence of DAFOR. Table 1 is Reliability data for the IEEE-RTS 400-MWand 350MW generating units. 


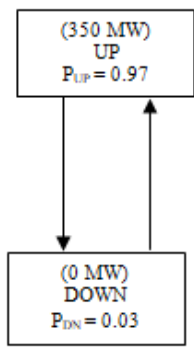

Figure 5. The two state models for $350 \mathrm{MW}$ generating unit

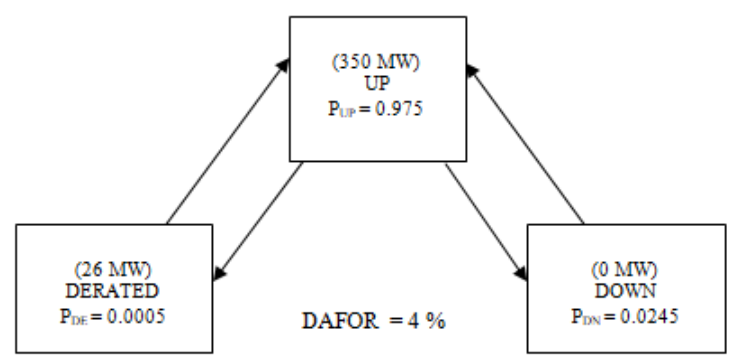

Figure 6. The three state models for 400-MW generating unit

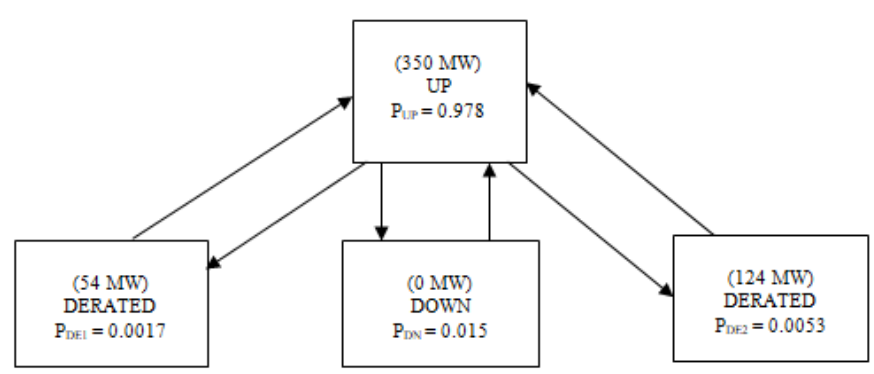

Figure 7. The four state models for $350 \mathrm{MW}$ generating unit

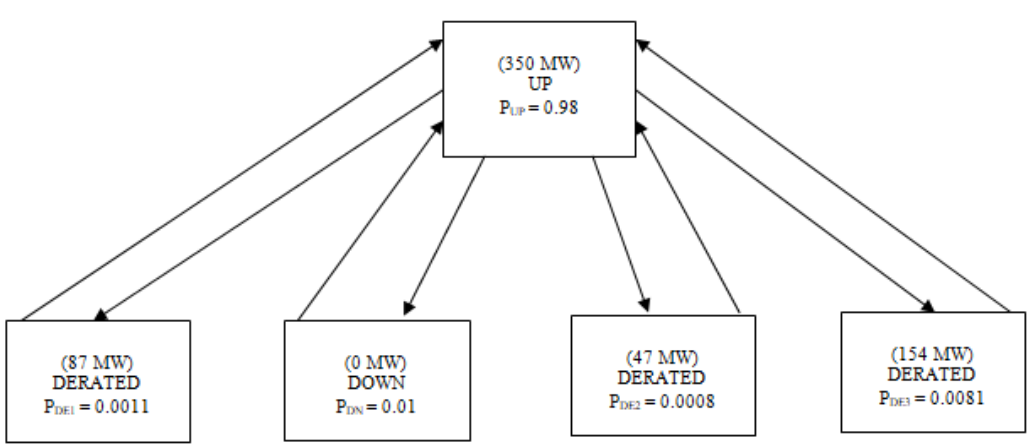

Figure 8. The five state models for $350 \mathrm{MW}$ generating unit

Table 1. Reliability data for the IEEE-RTS 400-MWand 350-MW generating units

\begin{tabular}{cccccccccc}
\hline $\begin{array}{c}\text { Model } \\
\text { Type }\end{array}$ & $\begin{array}{c}\text { Capacity } \\
\text { (MW) }\end{array}$ & $\begin{array}{c}\text { Curtailment } \\
\text { Capacity 1 } \\
\text { (MW) }\end{array}$ & $\begin{array}{c}\text { Curtailment } \\
\text { Capacity 2 } \\
\text { (MW) }\end{array}$ & $\begin{array}{c}\text { Curtailment } \\
\text { Capacity 3 } \\
\text { (MW) }\end{array}$ & $\mathrm{P}_{\mathrm{DN}}$ & $\mathrm{P}_{\mathrm{DE} 1}$ & $\mathrm{P}_{\mathrm{DE2} 2}$ & $\mathrm{P}_{\mathrm{DE3} 3}$ & DAFOR \\
\hline Two & 400 & - & - & - & 0.05 & - & - & - & - \\
state & 350 & - & - & - & 0.03 & - & - & - & - \\
Three & 400 & 70 & - & - & 0.0374 & 0.0074 & - & - & 0.07 \\
state & 350 & 65 & - & - & 0.0245 & 0.0005 & - & - & 0.04 \\
Four & 400 & 110 & 45 & - & 0.0311 & 0.0081 & 0.0018 & - & 0.07 \\
State & 350 & 63 & 40 & - & 0.015 & 0.0017 & 0.0053 & - & 0.04 \\
Five & 400 & 115 & 38 & 44 & 0.0301 & 0.0012 & 0.0073 & 0.0019 & 0.07 \\
State & 350 & 55 & 48 & 42 & 0.01 & 0.0011 & 0.0008 & 0.0081 & 0.04 \\
\hline
\end{tabular}

The selection of the nominated derated capacity level in a multi-state generating unit model is important in some circumstances and should be done carefully as the system and load bus indices can be considerably affected in these cases. From the Table 1, it is clearly implies that the increase in derated adjusted forced outage rate reduced the down time. The curtailment capacities can be utilized through the reserved generating units and perceive the reliability of system. Here three derated states were involved to arrive the optimized load point indices which are a gratis for the reliability indices in generation units. 


\section{INCORPORATING SYSTEM PERFORMANCE INDICES IN COMPLEX SYSTEM ADEQUACY EVALUATION}

The performance indices proposed for the complex system adequacy assessment are having appropriate predcion in the bulk electrical system. The future expansion and planning depends on the predictive power system reliability indices. The statistical performance indices give the actual behaviour of the operating system. In the Performance-based Regulation (PBR) approach, the failure rate and the period of extremis stages will be identified and the same is equated with the distribution companies cost in the electricity market. The PBR approach is already in the test phase in some electricity distribution diligence utilities[19]. In the field of composite generation and transmission systems, PBR is under consideration and bulk electricity system performance indices will be key factors in this regulatory approach. The most common system performance indices in composite systems are the System Average Interruption Frequency Index (SAIFI), the System Average Interruption Duration Index (SAIDI), the System Average Restoration Index (SARI) and the Delivery Point Unreliability Index (DPUI). It is important for utilities to also have the ability to predict how system performance indices may change with time as this is directly related to their revenues and costs (2) shows the calculation of the SAIFI for the specified Voltage Class and Supply Type using the ENLC of each load bus.

$$
\text { SAIFI }=\frac{\left.\sum_{N \epsilon M}^{\mathrm{n}}\left(E N L C_{i}\right)+\sum_{N \epsilon L}^{\mathrm{n}} \mathrm{ENLC}_{i}\right)}{\mathrm{N}}
$$

The calculation of the SAIDI for the specified Voltage Class and Supply Type using the PLC of each load bus as shown in (3)

$$
\text { SAIDI }=\frac{\sum_{\mathrm{N} \epsilon \mathrm{M}} \mathrm{PLCi} * 8760+\sum_{N \in L} \mathrm{PLCi} * 8760}{\mathrm{~N}}
$$

The calculation of the SARI based on SAIDI and SAIFI as shown in (4)

$$
\text { SARI }=\frac{\text { SAIDI }}{\text { SAIFI }}
$$

Bulk electricity system delivery point performance can be affected by many variables. Factors such as station transformer configurations, the load curtailment philosophy, system modifications and the system peak load are considered and analyzed in the next section to show they affect the system performance indices The system performance indices change with the time due to many factors including the aging of facilities, system growth and operating philosophy and the weather, etc. Multiple circuit supply at a delivery point is more reliable than single circuit supply. The benefit associated with the increased investment can be assessed in terms of the predicted system performance indices. Delivery points served by higher voltage transmission tend to have better service performance indices than those served at lower voltages. The benefits associated with increased voltage levels can be assessed using the estimated system performance indices and considered with the required investment in the decision making process.

\section{IDENTIFYING TRANSMISSION DEFICIENCIES IN COMPLEX SYSTEMS}

In this section, a procedure is presented to identify transmission deficiencies in composite generation and transmission systems. The procedure includes three segments: base case analysis, factor analysis and remedial modifications

\subsection{Base case analysis}

Perform a base case analysis and determine the load point and system reliability indices as a function of the peak load. The combination of the load point indices and the system indices is then used to provide an indication of the system weak points. The variation in the load point and system reliability as a function of the peak load is examined to determine the least reliable load buses in the base case of IEEERTS. The analysis is focused on the EENS at the load buses, the system EENS and the performance indices of SAIFI and SAIDI. Additional indices can be used if the complexity is varied.

\subsection{Factor analysis}

The individual effect on the load point and system indices of generation and transmission facility failures is then examined. The key factors (generation or transmission) that influence the load point and 
system reliability indices are then determined. Power system containing weaker areas from the viewpoint of composite system reliability is found out through the factor analysis with the help of reliability indices. Specialized actions can then be taken to cure the problems and strengthen the system. The analysis examines the reliability of the IEEERTS with the generation system or the transmission system is assumed to be completily reliable which is having sufficient adequacy and security.

\subsection{Remedial modifications}

The system is then modified by adding transmission lines in through the indices obtained through the reliability assessment. The modification can be considered for the different peak load and the associated reliability indices will be calculated to authenticate the security and adequacy of the syatem. A range of modifications should be considered and the results compared with those of the base case to determine the benefits associated with the different load point indices and factor analysis. The Expected Energy Not Supplied (EENS) is calculated from the load curtailments and the associated average frequency and duration index and it is given in (5).

$$
E E N S=\sum_{i}^{n} C L_{i} F_{i} D_{i}
$$

The EENS shows the curtailments for different peak loads in the system which is associated with the Frequency (Fi) and Duration ( $\mathrm{Di}$ ) at the ith state. The variables for reliability assessment present in the generating units and the load points were pretentious by the introduction of derated states. The base case IEEERTS is modified by the obtained performance indices in the system and the weaker areas in the test system is modified with the different peak loads. The corresponding indices for the Modified Reliability Test System (MRTS) are offered to maintain adequacy and security of the restructured system. The reliability indices for the modified system are shown in the Table 2.

Table 2. System reliability indices for the MRTS at different peak load levels

\begin{tabular}{lccccc}
\hline \multicolumn{5}{c}{ System Indices } & \multicolumn{5}{c}{ Peak Laod(MW) } \\
& 4700 & 4900 & 5100 & 5300 & 5500 \\
\hline EENS(MWh/yr) & 1.195 & 6.104 & 27.378 & 106.99 & 270.615 \\
SAIFI & 0.0003 & 0.0009 & 0.003 & 0.014 & 0.031 \\
SAIDI & 0 & 0 & 0.02 & 0.12 & 0.393 \\
SARI & 0 & 0 & 6.666 & 8.571 & 12.677 \\
\hline
\end{tabular}

From the Table 2, it is clearly renowned that the variation of EENS is proportional to the increase in peak loads and the curtailment will be minutest till the peak load of $5100 \mathrm{MW}$. So the capability limits of the restructured system can be maintained through the remedial modifications of existing base case. The reliability analysis through different states and the improvements by the accrual of derating states are comandable.

\section{CONCLUSION}

It has been acknowledged that the modelling of large engendering units in generating capacity and system adequacy assessment by the state models through DAFOR yields finite results. A series of studies are conducted to scrutinise the impacts of multi-state generating unit models on the consignment point and system reliability of MRTS systems. DAFOR plays a vital roll to decrease the down time through the curtailed capacity in the derating states. The ambiguity associated with accumulation of new generation units depends on many factors including the load growth and the risk associated in the speculation area. The generation uncertainty directly affects the load point indices in the transmission system. Transmission deficiencies have customarily been identified by conducting power flows; short-circuit analyses, voltage collapse studies, contingency analyses and stability analyses. The possible paucities were acknowledged based on the complex power system reliability analysis. The research work clearly illustrates the composite reliability evaluation on the test networks yields many allusions in planning and operating decisions

\section{REFERENCES}

[1] R. Billinton and R. N. Allan, Reliability Evaluation of Power Systems,2nd ed. New York: Plenum, 1996.

[2] R. Billinton, "Bibliography on the application of probability methods in power system reliability evaluation, " IEEE Transactions, Vol. PAS-91, No. 2, pp. 644-660, Mar-Apr 1972. 
[3] IEEE Sub-Committee Report, "Bibliography on the application of probability methods in power system reliability evaluation 1971-1977”, IEEE Transactions, Vol. PAS-97, No. 6, Nov-Dec 1978.

[4] Salvaderi, L, "Electric Sector Restructuring in Italy," IEEE Power Engineering Review, Vol. 20, No. 4, pp. 12-16, Apr 2000.

[5] N.Mahiban Lindsay and A.K.Parvathy, "Enhancing Power System Reliability using Multiple FACTS Devices," International Journal of Scientific and Engineering Research, Volume 4,PP 141-145, March-2013.

[6] Harris, P. G., "Impacts of Deregulation on the Electric Power Industry," IEEE Power Engineering Review, Vol. 20, No. 10, pp. 4-6, Oct 2000.

[7] Abdoo, R. A., "Industry Restructuring Deregulation and Competition", IEEE Power Engineering Review, Vol. 19, No. 7, pp. 16-18, Jul 1999.

[8] N.Mahiban Lindsay and A.K.Parvathy, Simulation and application on Power system reliability for bulk electrical system, LNEE series of Springer, Volume 326, pp 1139-1147,. Nov 2014.

[9] Ali Mansouri, Ali Aazami, Amin Omidian, Ehsan Mohamadian, Rahmat Aazami, "Evaluation of Power System Reliability Considering Direct Load Control Effects," International Journal of Electrical and Computer Engineering, Vol. 3, No. 2, pp. 254-259, April 2013.

[10] P. Ramesh, M. Damodara Reddy, "Power Transfer Capability \& Reliability Improvement in a Transmission Line using Distributed Power- Flow Controller," International Journal of Electrical and Computer Engineering, Vol.2, No.4, pp. 553-562, August 2012.

[11] Rudnick, H., "Market Restructuring In South America," IEEE Power Engineering Review, Vol. 18, No. 6, pp. 3-6, Jun 1998.

[12] Draper, E. L., "Assessment of Deregulation and Competition," IEEE Power Engineering Review, Vol. 18, No. 7, pp. 17-18, Jul 1998.

[13] Lamoureux, M. A., "Evaluation of Electric Utility Restructuring in the UK," IEEE Power Engineering Review, Vol. 21, No. 6, pp. 6-9, Jun 2001.

[14] Read, W. S., "Electric Utility Restructuring in North America," IEEE Power Engineering Review, Vol. 21, No. 5, pp. 6-9, May 2001.

[15] Puttgen, H.B., Volzka, D.R., Olken, M.I., "Restructuring and Reregulation of the US Electric Utility Industry," IEEE Power Engineering Review, Vol. 21, No. 2, pp. 8-10, Feb 2001.

[16] S. Surender Reddy, "Optimal Placement of FACTS Controllers for Congestion Management in the Deregulated Power System,” International Journal of Electrical and Computer Engineering, Vol. 8, No. 3, pp. 1336-1344, June 2018.

[17] McClanahan, R. H., "Electric Deregulation,” IEEE Industry Application Magazine, Vol. 8, No. 2, pp. 11-18, Mar/Apr 2002.

[18] L. Philipson and H. L. Willis, "Understanding Electric Utilities and Deregulation," Marcel Dekker, New York, 1999.

[19] R. Billinton and W. Li, "A System State Transition Sampling Method for Composite System Reliability Evaluation," IEEE Transactions on Power Systems, Vol. 8, No. 3, pp. 761-771, August 1993.

[20] R. N. Allan and J. Roman, "Reliability Assessment of Generation Systems Containing Multiple Hydro Plant Using Simulation Techniques," IEEE Transactions on Power Systems, Vol. 4, No. 3, pp. 1074-1080, August 1989.

\section{BIOGRAPHIES OF AUTHORS}

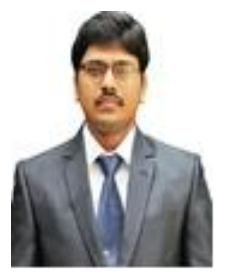

N.Mahiban Lindsay was born in Tamilnadu, India. He graduated from the faculty of Electrical Engineering from Anna University, Chennai, India. He received his masters in Power System Engineering from Anna University, Chennai, India. Currently he is a Professor of Electrical and Electronics Engineering at Hindustan University. He is also a visiting faculty at Anna University. His major research work has spun around power system reliability.

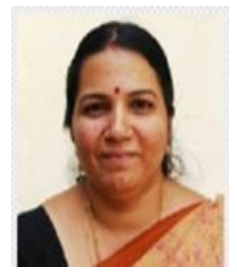

A.k.Parvathy was born in Kerala, India. She graduated from the faculty of Electrical Engineering from Government college of Engineering, Thrissur, Kerala and obtains masters from the same. She completed PhD in Electrical Engineering from Anna University in 2013. Her thesis is "Analysis and Adaptation of Quadratic Linearization to the Control of Permanent Magnet Synchronous Motor". She served as lecturer in Amrita Institute of Technology and Science, Coimbatore for one year. She served as Assistant Engineer in Kerala State Electricity Board and monitored the erection of $220 \mathrm{KV}$ substation in Brahmapuram. She then served as Senior Lecturer in Sri Venkateswara College of Engineering, Chennai. Currently she is serving as the Professor and Head of Electrical Engineering Department in Hindustan University. Her research areas focused on Power system and Power Electronics. 